\title{
TRANSFORMING FACULTY DEVELOPMENT PROGRAMS FROM FACE-TO-FACE TO BLENDED/HYBRID ENVIRONMENTS
}

\author{
Dalia Hanna \\ Ryerson University (CANADA)
}

\begin{abstract}
Faculty development programs are critical to the success of the learning and teaching process in higher education. With the rapid development of blended courses there is a need to transform the face-to-face faculty development programs to blended programs. The transformation requires instructors to examine new teaching methods and techniques, and obtain new skill set to ensure the success of the learning process and students' engagement in the new environment. Blended teaching is not just about transferring part of the training course online, but involves creating online activities that engage learners and complement the face-to-face activities. The role of the instructors changes from lecturer to facilitator of learning, coach and collaborator. Through participation in blended learning environments, instructors could experiment the new teaching strategies in a collaborative and safe environment.

This paper presents the process, benefits and challenges of transforming the Instructional Skills Workshop (ISW) for instructors from a three-day twenty four hours intensive format to four-week blended format. The Instructional Skills Workshop is peer-based training in which participants interact and present lessons in small groups to develop effective instructional skills through the use of constructive feedback strategies. Strategies associated with the re-design process which is based on the instructional design theories and principles will be presented. The paper presents data from formative and summative evaluations on communication, instructional skills and course design. The recommendations will address best practices that could be used to transform many faculty development programs from face-to-face to blended formats.
\end{abstract}

Keywords: Hybrid, Online, Blended Teaching, Blended Learning, Faculty Development Programs, Instructional Skills.

\section{ABOUT THE INSTRUCTIONAL SKILLS WORKSHOPS}

\subsection{Introduction}

Developed in 1970s in British Colombia, Canada, The Instructional Skills Workshop (ISW), adapted a competency-based adult education [1] to support learning objectives. It evolved thought years and adapted a learning outcomes approach integrating performances and mastery of basic curriculum design skills [1]. "The ISW Program is a comprehensive three-level instructor development program which start with the Instructional skills workshops, the Facilitator Development Workshop and the Instructional Skills Workshop Facilitator Trainers [1].

Using an intensive experiential learning approach, participants are provided with information on the theory and practice of teaching adult learners, the selection and writing of useful learning objectives with accompanying lesson plans, techniques for eliciting learner participation, and suggestions for evaluation of learning [1]. The ISW is a peer based model and designed to enhance the teaching effectiveness of both new and experienced of educators through developing new teaching skills and mastering effective feedback [1].

Participants are required to plan and deliver three mini-lessons and provide constructive feedback to peers both oral and in writing; future they participate in collaborative and experiential learning activities. Upon completing all the ISW requirements participants receive a certificate which is internationally recognized.

\subsection{ISW Structure}

The original format of the ISW is a 24 hours, three-day intensive workshop offered within a small group of eight to ten participants and two to four ISW trained facilitators. This group is then divided into 
two small groups of four to five participants. In this safe environment, participants prepare three minilessons using an objective based model and present their lessons in 10 minutes. Other participants then provide the presenter with written feedback and facilitated oral feedback about their teaching.

Using adult learning principles, in the large group, participants discuss various teaching and learning topics including active learning, learning styles, characteristics of effective teaching and characteristics of effective feedback.

\subsubsection{ISW at Ryerson University}

At Ryerson University, the faculty development office, provide the ISW for instructors, teaching assistants and graduate assistants (TA/GAs). So far, 94 instructors completed the face-to-face ISW through 12 sessions and 16 completed the hybrid ISW through 2 sessions. For TA/GAs there were 8 sessions with 57 participants. Ryerson has 16 trained facilitators and 2 trainers. The author is one of the two trainers and facilitated 11 sessions for both instructors and TA/GAs. The facilitators are faculty members and educational developers. The sessions run with two to four facilitators.

\section{HYBRID TEACHING AND LEARNING}

Hybrid/blended teaching and learning means that $30 \%$ to $79 \%$ of the course materials and the activities related to the course goals and objective could be delivered electronically [2]. In this paper, the author will use hybrid and blended words alternatively with both carrying the same meaning.

Teaching in distance learning environments requires a shift towards student-centered learning from instructor-centered or lecture-centered approaches [2]. Furthermore, the instructor's role shift from the lecturer role to a facilitator or a coach role; the content changes from just text books to customized materials, and from considering credit hours to performance standards [2].

\subsubsection{Needs Assessment}

At Ryerson University, the ISW took the form of the three-day format since 2009. The main challenge was to attract full-time instructors as it was difficult for them to empty their schedules for three complete days from 9:00 am to 5:00 pm in addition the time needed to prepare the three mini-lessons.

Based on interview with faculty, evaluation forms from the face-to-face participants and verbal communication with faculty during the workshops. It was determined that we will need to adapt a new strategy to reach out to more faculty. Speaking with administrators and many instructors on campus, the blended learning environment emerged as an effective strategy which instructors at Ryerson University may accept and experiment. Some were already experimenting blended learning and flipped classroom and there was a need among faculty to provide training on how to teaching in the blended learning environment.

\subsubsection{Workshop Re-Design Process}

Hybrid teaching is not just about transferring parts of the course online, but involves creating online activities that engage students and complement the face-to-face activities [3]. Furthermore, hybrid/blended courses should incorporate teaching strategies that enhance and balance learnerlearner interactions, learner-content interactions and learner-instructor interactions [4].

To offer the ISW in the blended environment, we added new objectives in relation to understanding the context and the technology used. In addition, the activities had to be aligned with the new learning objectives. Table 1 provide an overview of the face-to-face and the blended objectives. 
Table 1. The face-to-face and blended ISW objectives

\begin{tabular}{|c|c|}
\hline ISW Objectives from the ISW Handbook [1] & $\begin{array}{l}\text { New objectives for the Blended Workshop (In } \\
\text { addition to the objectives listed in column } 1\end{array}$ \\
\hline $\begin{array}{l}\text { - } \text { Consider the variable needs of learners } \\
\text { - Write useful, practical lesson plans } \\
\text { - } \quad \text { Use questions and question sequences } \\
\text { - } \text { effectively during a lesson } \\
\text { - } \text { Apply common instructional media and } \\
\text { resources competently } \\
\text { - Make use of basic techniques to test for } \\
\text { learning } \\
\text { - Provide and receive constructive } \\
\text { feedback }\end{array}$ & $\begin{array}{l}\text { - Examine the characteristics of teaching in } \\
\text { a hybrid environment } \\
\text { - Make use of basic techniques to test for } \\
\text { learning } \\
\text { - Employ learning objectives or expressive } \\
\text { outcomes to inform learners of } \\
\text { expectations and intentions }\end{array}$ \\
\hline
\end{tabular}

As indicated in Table 1, the focus in the blended environment is on understanding the new learning environment and mastering the technology tool as well as the teaching strategies.

\subsubsection{The design and Format}

Based on all the above the following was the suggested format for the hybrid ISW for a total of 24 hours as required by the ISW International Advisory Committee:

- Online: two week period for pre-work and pre-readings - approximately four hours actual work time.

- Face-to-face: half day on-site for introductions, instructions and some class work.

- Online: approximately eight additional hours of off-site work in Blackboard.

- Face-to-face: three half days on-site to practice teaching - mini-lessons (additional preparation time will be required to plan the mini-lessons)

A new syllabus was developed and posted in the learning management system; it included details about each module and expectations for participating in the online discussions, face-to-face components and lesson plans. In addition, a rubric was developed to provide course expectations to participants.

All the large group discussions transformed to be in the online course site in Blackboard. Participants answer guided questions and are required to respond to at least two of their peers in eth same group or the other group. All participants could view all entries and participate as needed.

For the two hybrid sessions, the author if this paper was one of the facilitators and is responsible for facilitating the online components and in class activities. The other facilitator is an experienced full time faculty member who ran many face-to-face sessions and is responsible for facilitating the face-toface parts only.

To fulfil the mastery of the technology tool, participants were provided with tutorials on how to post on the discussion board and navigate the system. They were also asked to post a goodbye message to peers through VoiceThread. A tutorial on how to use VoiceThread was posted on the course site.

\subsubsection{Implementation}

The communication targeted faculty on the campus wide listservs and on the ISW website to cleary indicate the new format and the reason for it, which is to accommodate their busy schedules. In the workshop immediately filled up with almost $62.5 \%$ full time faculty (5 out of 8 ) which is an improvement from previous ISWs. In the past we used to get ( $12.5 \%$ to $25 \%, 1$ or 2 out of 8$)$ full time faculty.

The blended ISW was implemented twice. In the first session, which was a pilot, we met as a large group on the first face-to-face meeting and reviewed the online components. 


\subsubsection{Benefits to Faculty}

Research indicates that there are many benefits for bended learning. For example, blended courses support the shift from lecture-centered to student-centered instruction. Experienced instructors could create individualized learning experience for learners thus enhancing their learning experience [5]. Hybrid courses present integration of more social and progressive instructional models; an example of the use of simulations [2]. Additionally, as online and face-to-face activities and interactions can vary widely in hybrid courses, it could represent a starting point for instructors who are used to face-to-face instruction and looking into shifting to virtual and online instruction therefore creating a new teaching opportunity for faculty which can help them solving a problem in a course [3]. Finally, Hybrid courses provide an opportunity for faculty to utilize the best of the web and the best of the face-to-face environments [6].

In the two hybrid workshops at Ryerson, instructors explained that they learned new insights into the benefits and challenges of online teaching and how to participate in online activities without sacrificing the face-to-face experience. One participant indicated the he will develop lesson plan into his future lectures and will incorporate videos and technology tools in his outline. This provides an indication that there is a shift in attitude.

\subsubsection{Challenges}

Research indicates that blended courses require learners and teachers to adapt to two different delivery models of education which may cause difficulty and confusion [2]. If institutions schedule classrooms tightly, facility problems affect a proportionally larger number of students. In addition, there is still a digital divide such that not all students have access to high speed internet, computer hardware, and software to avail themselves of online delivery in any format [2]. Space limitations and scheduling problems could affect in class activities.

The main challenge was that many instructors were not familiar with the Blackboard site and never participated in online activities. In addition, participants indicated that the workload was heavy or heavier than expected. Participants asked for an additional time continue the online discussion to continue in class. In the second hybrid ISW, we included an extra half-hour for the large group to meet and continue the discussions as needed. 


\section{REFERENCES}

[1] ISW International Advisory Committee. (2006). Instructional Skills Workshop Handbook. Available from http://iswnetwork.cal

[2] Simonson, M., Smaldino, S., Albright, M., \& Zvacek, S. (2012). Teaching and learning at a distance: Foundations of distance education (5th ed.). Boston, MA: Pearson.

[3] University of Wisconsin Milwaukie. (2012Hybrid courses: Faculty resources. Retrieved from http://www4.uwm.edu/ltc/hybrid/faculty_resources/advantages.cfm

[4] Dashaw, B., \& Lee, R. (2011). Designed learner interactions in blended course delivery. Journal of Asynchronous Learning Networks. 15(1), 68-76.

[5] Dizuban, D., Hartman, L., \& Moskal, D. (2004, March 30). Blended learning. EDUCAUSE Center for Applied Research Bulletin.

[6] Osguthorpe, R. T., \& Graham, C. R. (2003). Blended learning environments: Definitions and directions. The Quarterly Review of Distance Education, 4(3), 227-233 